\title{
Evaluation of nutritional status in children hospitalized in Mofid Children's Hospital, Tehran, Iran
}

\author{
Ali-Akbar Sayyari ${ }^{1}$, Farid Imanzadeh ${ }^{1}$, Mehdi Moradi ${ }^{1}$, Hazhir Javaherizadeh ${ }^{2}$, Ahmad-Reza Shamshiri ${ }^{3}$ \\ 1Department of Pediatric Gastroenterology, Mofid Children's Hospital, Shahid Beheshti University of Medical Sciences, \\ Tehran, Iran \\ 2Faculty of Medicine, Ahvaz Jundishapur University of Medical Sciences, Ahvaz, Iran \\ 3Pediatric Infectious Research Center, Mofid Children's Hospital, Shahid Beheshti University of Medical Sciences, Tehran, Iran
}

Prz Gastroenterol 2013; 8 (2): 120-125

DOI: $10.5114 /$ pg.2013.34837

Key words: failure to thrive, dysphagia, vomiting, children, hospital-acquired malnutrition.

Address for correspondence: Assis. Prof. Hazhir Javaherizadeh, Faculty of Medicine, Ahvaz Jundishapur University of Medical Sciences, phone: +98 611333 7681, fax: +98 611333 7681, e-mail: hazhirja@yahoo.com

\begin{abstract}
Introduction: Children who are admitted to the hospital are at high risk of developing malnutrition. Malnutrition may cause complication during and after hospitalization.

Aim: To determine the frequency of weight reduction among children hospitalized in a tertiary referral hospital in Tehran. Material and methods: Patients aged $\geq 1$ month and length of hospital stay $>48 \mathrm{~h}$ were included in this study. Duration of this study was 3 months from $1^{\text {st }}$ November 2006. Age, sex, disease severity, respiratory difficulty, calorie intake, diarrhea, vomiting, dysphagia, length of hospital stay, and type of disease (surgical vs. medical) were assessed during admission. Children with weight reduction < $2 \%$ were placed in group I. Data were analyzed by SPSS ver. 14.0 (Chicago, IL, USA).

Results: In this study 322 cases were included. Group I included 156 patients (48.44\%) and group II included 110 patients (51.56\%). One hundred and fifty patients (46.6\%) had caloric intake less than $50 \%$ and 172 (53.4\%) had caloric intake $\geq 50 \%$. Analysis showed that calorie intake equal to or less than $50 \%$, disease grade 2 and 3 , duration of hospital stay, diarrhea, and dyspnea had a significant correlation with weight reduction $\geq 2 \%(p<0.05)$.

Conclusions: Calorie intake $<50 \%$, disease severity, length of hospital stay, diarrhea, and dyspnea were significantly higher among cases with weight reduction $\geq 2 \%$ than cases with weight reduction $<2 \%$.
\end{abstract}

\section{Introduction}

Malnutrition is the imbalance between the supply of nutrition and energy and the body's demand for these to ensure growth, maintenance, and specific function [1]. Children who are admitted to the hospital are at high risk of developing malnutrition, especially children with underlying disease [2]. In Asian, Latin American, Near Eastern and African countries, hospital-acquired malnutrition continues to be an important co-morbidity in children, affecting their outcome [3]. In different countries, $21 \%$ to $80 \%$ of children showed malnutrition following hospital admission [4]. It is known that mortality and morbidity rates are greater in undernourished patients [57]. Around $70-80 \%$ of malnourished patients enter and leave the hospital without identification and treatment of their malnutrition [8, 9]. However, hospital-based malnutrition has been described with increasing frequency in hospitalized and chronically ill children in economically advantaged countries such as the United States and European countries [3]. In a tertiary hospital in France, Sermet-Gaudelus et al. found that $62 \%$ of children had lost weight during their hospital stay [10]. The nutritional status of children often declined after admission to the hospital, resulting in early and serious consequences, such as slowing of growth and increased susceptibility to various infections [10-12]. Although hospital-acquired malnutrition is frequently associated with a risk of adverse clinical events and longer hospital stay leading to higher health care costs [12], it is a problem that remains largely underestimated and often unrecognized [13].
Aim
The aim of this study was to evaluate nutritional sta- tus among children hospitalized in our tertiary hospital. 


\section{Material and methods}

This prospective study was carried out in Mofid Children's Hospital, a referral children's hospital in Tehran, Iran. Duration of the study was 3 months during 2006. Children aged > 1 month with duration of admission $>48 \mathrm{~h}$ were included in this study. Exclusion criteria were severe liver or kidney disease, severe fluid and electrolyte imbalance, special diet regimen (diabetic, ketogenic), and patients without parental agreement. Age, sex, weight, \% of body weight reduction, disease intensity, type of disease, diarrhea, vomiting, calorie intake, dyspnea, dysphagia, severity of malnutrition, and duration of hospital admission were recorded for each patient.

A digital baby scale (Seca, Germany, $\pm 5 \mathrm{~g}$ ) was used for weight measurement in children $<15 \mathrm{~kg}$ and an analog scale (Rasa, Iran, $\pm 100 \mathrm{~g}$ ) was used for children $>15 \mathrm{~kg}$. Height was measured in a recumbent position in children $<3$ years. A stadiometer was used for height measurement for children $>3$ years in a standing position.

Waterlow criteria and NCHS (National Center for Health Statistics) tables were used for determination of acute or chronic malnutrition at the moment of hospitalization.

Weight for height (wasting) was used to define acute malnutrition. Height for age (stunting) was used to determine chronic malnutrition. Acute hospital malnutrition in this study was defined as more than $2 \%$ weight reduction after admission. This endpoint criterion was obtained from the Sermet-Gaudelus study [10]. Weight reduction was calculated from the formula WR = $($ Wad - Wd)/Wad $\times 100$, where Wad - weight at admission, $\mathrm{Wd}-$ weight at discharge.

According to WR patients were divided into two groups. Group I consisted of patients with WR $<2 \%$ and group II included cases with WR $\geq 2 \%$.

According to the classification of disease by the American Academy of Pediatrics and the American Nutrition Association, patients were classified in 3 groups $(1-$ mild, 2 - moderate, 3 - severe) [14-16]. Grade I conditions include mild stress factors, e.g., admission for diagnostic procedures, minor infection, other episodic illnesses, or minor surgery. Grade II conditions include moderate stress factors, e.g., severe but not life-threatening infection, routine surgery, fracture, chronic illness without deterioration, or inflammatory bowel disease. Grade III conditions include severe stress factors, e.g.; acquired immunodeficiency syndrome, malignancy, severe sepsis, major surgery, multiple injuries, acute deterioration of chronic disease, or major depression.

\section{Statistical analysis}

Analysis was done by SPSS ver. 14 (SPSS Inc, Chicago, IL, USA). Fisher exact test and Pearson $\chi^{2}$ test were used for correlation.

\section{Results}

In this study, 173 (53.7\%) male and 149 (46.3\%) female patients were included $\left(p=0.058, \chi^{2}=3.58\right)$. Two hundred and sixty-six patients (70.2\%) were admitted in medical wards and 92 (29.8\%) in surgical wards ( $p=0.00001$, $\left.\chi^{2}=104.97\right)$.

Acute malnutrition was noted in $27 \%$ of cases. Chronic malnutrition was found in $40.1 \%$ of cases (Table I). Chronic malnutrition was significantly more common than acute malnutrition $\left(p=0.0004, \chi^{2}=12.29\right)$. There was no significant difference between prevalence of mild acute and mild chronic malnutrition ( $p=0.56$ ) (Table I). Of 322 patients, duration of hospital staying was 1 week in $168(61.5 \%)$ cases $(p=0.00001)$. Weight loss $\leq 2 \%$ was noted in $156(41.44 \%)$ cases ( $p=0.000001)$ (Table II).

Cases according to minor, moderate and severe risk factors were classified into 3 categories (Table III). Minor surgery, gastroenteritis, and urinary tract infection were the most common minor risk factors $(p<0.05)$. Usual surgery was the most common moderate risk factor $\left(p=0.00001, \chi^{2}=58.8\right)$. Major surgery was the most common major risk factor ( $p=0.00001, \chi^{2}=67.1$ ) (Table III).

In our study, severe risk factors $(25.16 \%)$ were the least common risk factors among hospitalized children compared to minor (35.40\%) and moderate risk factors (39.44\%).

There was a significant correlation between weight loss and disease severity, duration of hospitalization,

Table I. Characteristics of cases according to sex, ward of admission, type of malnutrition, and calorie intake

\begin{tabular}{llll} 
Parameter & \multicolumn{2}{c}{ Results } & Significance \\
\hline Sex & Male $(173,53.7 \%)$ & Female $(149,46.3 \%)$ & $p=0.058, \chi^{2}=3.58$ \\
\hline Ward of admission & Medical $(226,70.2 \%)$ & Surgical $(96,29.8 \%)$ & $p<0.0001, \chi^{2}=104.97$ \\
\hline Malnutrition & Acute $(87,27.01 \%)$ & Chronic $(129,40.06 \%)$ & $p=0.0004, \chi^{2}=12.29$ \\
& Mild $(64,19.9 \%)$ & Mild $(70,21.8 \%)$ & $p=0.56, \chi^{2}=0.34$ \\
& Moderate $(15,4.6 \%)$ & Moderate $(46,14.3 \%)$ & $p=0.00003, \chi^{2}=17.4$ \\
& Severe $(8,2.5 \%)$ & Severe $(13,4 \%)$ & $p=0.26, \chi^{2}=1.23$ \\
\hline Calorie intake & $<50 \%(150,46.6 \%)$ & $>50 \%(172,53.4 \%)$ & $p=0.08, \chi^{2}=3.01$
\end{tabular}


Table II. Duration of hospitalization and weight loss during hospitalization

\begin{tabular}{|c|c|c|}
\hline Parameter & $N(\%)$ & Value of $p$ \\
\hline \multicolumn{3}{|c|}{ Duration of hospitalization [weeks] } \\
\hline 1 & $168(61.5)$ & 0.00001 \\
\hline 2 & $87(27)$ & \\
\hline 3 & $21(6.5)$ & \\
\hline$\geq 4$ & $16(5)$ & \\
\hline \multicolumn{3}{|c|}{ Total weight loss (during hospitalization) [\%] } \\
\hline $0-<2$ & $156(41.44)$ & 0.000001 \\
\hline $2-5$ & $103(31.98)$ & \\
\hline$>5-10$ & $51(15.88)$ & \\
\hline$>10$ & $12(3.72)$ & \\
\hline
\end{tabular}

and calorie intake, diarrhea, and dyspnea (Table IV). Acute malnutrition and chronic malnutrition had a significant correlation with acute hospital weight loss (Table IV).

\section{Discussion}

In the current study, 87 (27.01\%) and 129 (40.06\%) cases had acute $(\mathrm{W} / \mathrm{H})$ or chronic malnutrition $(\mathrm{H} / \mathrm{A})$ with varying degrees, respectively. Of all cases, 51.55\% of cases showed weight loss $\geq 2 \%$ during hospitalization. In the study by Mahdavi et al. on 140 children, $48.6 \%$ of cases were underweight according to Waterlow criteria [17]. Our findings were similar to the study by Mahdavi et al. [17]. But, in their study, weight was assessed at the moment of hospitalization. In our study, weight was assessed at the moment of hospitalization and during hospitalization.

In the study by Marek et al., BMI < $10 \%$ percentile was found in $19.3 \%$ of cases [18]. They concluded that undernutrition among children admitted to hospital is relatively frequent.

In the Hendricks et al. study, the prevalence of acute protein-energy malnutrition (weight for height) based on the Waterlow criteria was as follows: severe (1.3\%); moderate (5.8\%); mild (17.4\%), and none 75.5\% [19]. In our study, the prevalence of acute malnutrition using the same criteria was as follows: severe (2.5\%); moderate $(4.6 \%)$; mild (19.9\%); and none (73\%). The results of the two studies were similar.

In the Hendricks et al. study, the prevalence of chronic malnutrition (height for age) was as follows: severe (5.1\%); moderate (7.7\%), mild (14.5\%), and none (72.8\%) [19]. In our study, the following results were obtained: severe (4\%); moderate (14.3\%); mild (21.8\%); and none (59.9\%). The results of both studies were similar.

In the Dogan et al. study on 528 cases, evaluation of weight for age showed that $52.4 \%$ of cases had acute
Table III. Frequency of risk factors among our patients

\begin{tabular}{lc}
\hline Class I: Minor risk factor & $114(35.40 \%)$ \\
\hline Minor surgery & $34(10.55 \%)^{*}$ \\
\hline Gastroenteritis & $31(9.62 \%)^{*}$ \\
\hline Urinary tract infection & $20(6.22 \%)^{*}$ \\
\hline First seizure & $14(4.34 \%)$ \\
\hline Diagnostic procedure & $6(1.87 \%)$ \\
\hline Bronchiolitis & $5(1.56 \%)$ \\
\hline Others & $4(1.24 \%)$ \\
\hline Class II: Moderate risk factor & $127(39.44 \%)$ \\
\hline Usual surgery & $43(13.35 \%)^{*}$ \\
\hline Non-fatal infection & $26(8.07 \%)$ \\
\hline Non-intensive chemotherapy & $19(5.9 \%)$ \\
\hline Intractable seizure & $15(4.66 \%)$ \\
\hline Non-progressive chronic disease & $8(2.49 \%)$ \\
\hline Chronic diarrhea & $6(1.87 \%)$ \\
\hline Others & $10(3.10 \%)$ \\
\hline Class III: Severe risk factor & $81(25.16 \%)$ \\
\hline Major surgery & $43(13.37 \%)^{*}$ \\
\hline Progressive chronic disorder & $19(5.90 \%)$ \\
\hline Severe infection & $9(2.79 \%)$ \\
\hline Intensive chemotherapy & $6(1.86 \%)$ \\
\hline Others & $4(1.24 \%)$ \\
\hline Total & 322 \\
\hline$* p<0.05$ & \\
\hline
\end{tabular}

malnutrition [4]. In our study, $27.1 \%$ of cases had acute malnutrition using the same criteria.

In another study from Turkey, malnutrition rates varied between $55.1 \%$ and $56.6 \%$ in different regions of the country [20, 21]. In the Özer et al. study, acute malnutrition was noted in $18.9 \%$, chronic malnutrition in $15.4 \%$; acute and chronic malnutrition was $20.8 \%$ [20].

In Thailand, 55\% of patients aged 1-15 years suffered from acute malnutrition [22]. The rate of acute malnutrition in our study (27.01\%) was less than Thailand [22]. In Mexico, varying degrees of malnutrition were reported in $72.7 \%$ of hospitalized children [23]. In our study, varying degrees of acute or chronic malnutrition were present in $67.07 \%$ of cases, similar to Mexico [23].

This study showed that factors related to weight reduction during hospital stay in children were disease severity, calorie intake $<50 \%$, presence of acute or chronic malnutrition at the moment of hospital admission, presence of diarrhea and dyspnea, and length of hospital stay.

In the study by Oztürk et al., on 170 children admitted to hospital, they did not find a correlation between duration of hospital stay and the difference between 
Table IV. Correlation between possible factors and weight reduction

\begin{tabular}{|c|c|c|c|}
\hline Parameter & Group I $(n=156)$ & Group ॥ $(n=166)$ & Significance \\
\hline Sex & & & $p>0.05$ \\
\hline Male & $84(53.84 \%)$ & $89(57.05 \%)$ & \\
\hline Female & $72(46.16 \%)$ & 77 (46.38\%) & \\
\hline Age distribution [month] & & & $p=0.75, \chi^{2}=1.17$ \\
\hline $1-3$ & $13(8.33 \%)$ & $16(9.63 \%)$ & \\
\hline $4-12$ & $36(23.08 \%)$ & $41(24.69 \%)$ & \\
\hline $13-72$ & 74 (47.44\%) & $69(41.56 \%)$ & \\
\hline 72 & $33(21.15 \%)$ & $40(24.09 \%)$ & \\
\hline Calorie intake [\%] & & & $p<0.001, \chi^{2}=82.66$ \\
\hline$\leq 50$ & $32(20.51 \%)$ & $118(71.09 \%)$ & \\
\hline$>50$ & $124(79.48 \%)$ & $48(28.91 \%)$ & \\
\hline \multicolumn{4}{|c|}{ Duration of hospital stay [weeks] } \\
\hline 1 & $120(76.93 \%)$ & $78(46.99 \%)$ & $p=0.00001, \chi^{2}=30.43$ \\
\hline 2 & $27(17.31 \%)$ & $60(36.15 \%)$ & $p=0.0001, \chi^{2}=14.47$ \\
\hline 3 & $6(3.84 \%)$ & $15(9.03 \%)$ & $p=0.059, \chi^{2}=3.55$ \\
\hline$\geq 4$ & $3(1.92 \%)$ & $13(7.83 \%)$ & $p=0.014, \chi^{2}=5.95$ \\
\hline \multicolumn{4}{|l|}{ Acute malnutrition } \\
\hline Total & $22(14.10 \%)$ & $65(39.14 \%)$ & $p<0.00001, \chi^{2}=25.60$ \\
\hline Mild & $18(11.53 \%)$ & $46(27.71 \%)$ & $p=0.0002, \chi^{2}=13.21$ \\
\hline Moderate & $4(2.56 \%)$ & $11(6.62 \%)$ & $p=0.08, \chi^{2}=2.99$ \\
\hline Severe & 0 & $8(4.81 \%)$ & $p=0.01, \chi^{2}=5.85$ \\
\hline \multicolumn{4}{|l|}{ Chronic malnutrition } \\
\hline Total & $34(21.8 \%)$ & $95(57.22 \%)$ & $p<0.00001, \chi^{2}=42.05$ \\
\hline Mild & $24(15.38 \%)$ & $46(27.71 \%)$ & $p=0.007, \chi^{2}=7.18$ \\
\hline Moderate & $7(4.49 \%)$ & $39(23.49 \%)$ & $p=0.0001, \chi^{2}=23.73$ \\
\hline Severe & $3(1.93 \%)$ & $10(6.02 \%)$ & $p=0.06, \chi^{2}=3.49$ \\
\hline Ward of admission & & & $p=0.11, \chi^{2}=2.52$ \\
\hline Medical & $116(74.36 \%)$ & $110(66.26 \%)$ & \\
\hline Surgical & $40(25.64 \%)$ & $56(33.73 \%)$ & \\
\hline Dysphagia & $2(1.29 \%)$ & $3(1.81 \%)$ & $p>0.05$ \\
\hline Vomiting & $24(15.39 \%)$ & $15(9.04 \%)$ & $p=0.08, \chi^{2}=3.04$ \\
\hline Diarrhea & $21(1.67 \%)$ & $25(15.06 \%)$ & $p<0.0001, \chi^{2}=17.48$ \\
\hline Dyspnea & $8(5.13 \%)$ & $21(12.65 \%)$ & $p=0.01, \chi^{2}=5.55$ \\
\hline Disease grade & & & $p<0.0001, \chi^{2}=141.37$ \\
\hline 1 & $101(64.76 \%)$ & $13(7.83 \%)$ & $p<0.0001, \chi^{2}=113.90$ \\
\hline 11 & $52(33.33 \%)$ & $75(45.18 \%)$ & $p=0.02, \chi^{2}=4.79$ \\
\hline III & $3(1.93 \%)$ & $78(46.98 \%)$ & $p<0.0001, \chi^{2}=86.75$ \\
\hline
\end{tabular}

admission and discharge [24]. Most of the cases in their study were admitted to a non-surgical ward, but in our study $29.8 \%$ of cases were admitted to a surgical ward. The pattern of disease in the two studies was different and may be the cause of the different result.
We used criteria similar to those of the SermetGaudelus et al. study [10]. In contrast to the SermetGaudelus et al. study, there was no cardiac surgery in our hospital and there was no neurology ward in their hospital. In Sermet-Gaudelus's study, $71 \%$ of cases were 
admitted to a non-surgical and $29 \%$ to a surgical ward, similar to our study. For weight reduction (<2\%, $2-5 \%$, $>5-10 \%,>10 \%)$, in our study the results were as follows: $48.44 \%, 31.98 \%, 15.88 \%$, and $3.72 \%$. In the SermetGaudelus et al. study they were $19 \%, 28.7 \%, 14.5 \%$, and $2 \%$. There was a difference between the studies for WR $<2 \%$.

In the Rocha et al. study, $51.6 \%$ of cases had weight reduction during hospitalization [25]. In our study $51.58 \%$ of children had lost body weight $\geq 2 \%$. This finding is similar to the Rocha et al. study. In Rocha's study, nutritional status was classified in accordance with WHO criteria: malnutrition was severe if Z-scores were less than -3 SD, moderate from -2 SD to -3 SD, and mild from -1 SD to -2 SD. In our study, $70.2 \%$ of cases were admitted to non-surgical and $29.8 \%$ to surgical wards. Although there was a difference in pattern frequency of disease between our study and the Rocha et al. study [25], the rate of weight loss was similar. They excluded surgical disease from the study, but we included surgical cases in our study.

Intensive chemotherapy is grade III and is associated with bodyweight loss during hospitalization. Because of the confounding effect of tumor mass, use of body weight to assess nutritional study in pediatric cases has been misleading [26]. This confounding factor may explain why other authors have suggested that children with malignancy are at lower risk of malnutrition than children with other conditions [27].

As shown in most studies, there was a relatively high frequency of malnutrition among children admitted to hospitals around the world [10, 22, 23, 25]. Most studies used NCHS and WHO/CDC values for calculating W/A, $\mathrm{H} / \mathrm{A}$, and $\mathrm{W} / \mathrm{H}$. There were studies showing that local growth parameters may be more accurate for each country [28-30]. There is a lack of research using local growth parameters for calculating W/A, H/A, and W/H among hospitalized children.

\section{Conclusions}

Calorie intake $<50 \%$, duration of hospital stay, disease grade, diarrhea, and dyspnea had a correlation with acute hospital malnutrition. Minor, usual, and major surgery were the most common risk factors. Avoidance of unnecessary prolonged hospitalization may help to reduce the frequency of body weight loss among patients. Pediatric patients hospitalized in surgical wards should receive treatment by a pediatrician and a nutritional specialist.

\section{Acknowledgments}

We acknowledged all nurses in Mofid Children's Hospital.

\section{References}

1. Balint JP. Physical finding in nutritional deficiencies. Pediatr Clin North Am 1998; 45: 245-60.

2. Joosten KFM, Hulst JM. Prevalence of malnutrition in pediatric hospital patients. Curr Opin Pediatr 2008; 20: 590-6.

3. DeLegge MH, Drake LM. Nutritional assessment and enteral support of critically ill children. Gastroenterol Clin North Am 2007; 36: 1-22.

4. Dogan Y, Erkan T, Yalvac S, et al. Nutritional status of patients hospitalized in pediatric clinic. Turk J Gastroenterol 2005; 16: 212-6.

5. Leite HP, Isatugo MK, Savaki L, et al. Anthropometric nutritional assessment of critically ill hospitalized children. Rev Paul Med 1993; 111: 309-13.

6. Giner M, Laviano A, Meguid MM, et al. In 1995 a correlation between malnutrition and poor outcome in critically ill patients still exists. Nutrition 1996; 12: 56-7.

7. Uysal G, Sokmen A, Vidinlisan S. Clinical risk factors for fatal diarrhea in hospitalized children. Indian J Pediatr 2000; 67: 329-33.

8. Kelly IE, Tessier S, Cahill A, et al. Still hungry in hospital: identifying malnutrition in acute hospital admissions. Q J Med 2000; 93: 93-8.

9. McWhirter JP, Pennington CR. Incidence and recognition of malnutrition in hospital. BMJ 1994; 308: 945-8.

10. Sermet-Gaudelus I, Poisson-Salmon AS, Colomb V, et al. Simple pediatric nutritional risk score to identify children at risk of malnutrition. Am J Clin Nutr 2000; 72: 64-70.

11. Hendrike WH, Reilly JJ, Weaver RL. Malnutrition in children's hospital. Clin Nutr 1997; 16: 13-8.

12. Reilly JJ, Hull SF, Albert N, et al. Economic impact of malnutrition: a model system for hospitalized patients. JPEN J Parenter Enteral Nutr 1988; 12: 372-6.

13. Coats KG, Morgan SL, Bartolucci AA, Weinsier RL. Hospital associated malnutrition: a reevaluation 12 years later. J Am Diet Assoc 1993; 93: 19-31.

14. Reilly FM, Martineau JK, Moran A, et al. Nutritional screening. Evaluation and implementation of a simple nutrition risk score. Clin Nutr 1995; 14: 269-73.

15. Taylor BM, Bradford Harris A. Pediatric nutrition assessment identifying children at risk. J Am Diet Assoc 1997; 97 (Suppl): 5107-15.

16. Rolland-Cachera MF, Cole TJ, Sampe M, et al. Body mass index variations: centile from birth to 87 years. Eur J Clin Nutr 1991; 45: 13-21.

17. Mahdavi AM, Ostadrahimi A, Safaiyan A. Nurtional status of children hospitalized in Tabriz pediatric hospital, Islamic Republic of Iran, 2008. East Meditrr Health J 2011; 17: 36-40.

18. Marek A, Plata-Nazar K, Furtak J, et al. Undernutrition in hospitalized children. Part I. Med Wieku Rozwoj 2004; 8: 439-43.

19. Hendricks KM, Duggan C, Gallagher L, et al. Malnutrition in hospitalized pediatric patients: current prevalence. Arch Pediatr Adolesc Med 1995; 149: 1118-22.

20. Özer N, Urganci N, Usta A, et al. Determination of malnutrition in hospitalized children. T Klin J Pediatr 2001; 10: 133-8.

21. Genel F, Alihan F, Bak M, et al. Prevalence of anemia and malnutrition in hospitalized cases. T Klin J Pediatr 1997; 6: 173-7. 
22. Tienboon P. Nutritional status of pediatric patients: Maharaj Nakorn Chiang Mai Hospital. Thai Journal of Parenteral and Enteral Nutrition 1995; 6: 3-14.

23. Cortes RV, Nava-Flores G, Perez CC. Frequency of malnutrition in children in a tertiary level pediatric hospital. Rev Mexicana Pediatr 1995; 62: 131-3.

24. Oztürk Y, Büyükgebiz B, Arslan N, et al. Effects of hospital stay on nutritional anthropomethric data in Turkish children. J Trop Pediatr 2003; 49: 189-90.

25. Rocha GA, Rocha EM, Martins CV. The effects of hospitalization on the nutritional status of the child. J Pediatr (Rio J) 2006; 82: 70-4.

26. Smith DE, Stevens MC, Booth IW. Malnutrition at diagnosis of malignancy in childhood: common but mostly missed. Eur J Pediatr 1991; 150: 318-22.

27. Hendricks KM, Duggan C, Gallagher L, et al. Malnutrition in hospitalized pediatric patients. Current prevalence. Arch Pediatr Adolesc Med 1995; 149: 1118-22.

28. Fakharzadeh L, Javaherizadeh $\mathrm{H}$, Sabeti $\mathrm{F}$, et al. Are growth curves for Iranian school-aged children different from the NCHS standards? J Egypt Public Health Assoc 2011; 86: 90-4.

29. Musaiger AO, Gregory WB, Haas JD. Growth patterns of school-children in Bahrain. Ann Hum Biol 1989; 16: 155-67.

30. Hamil PV, Drizd TA, Johnson CL, et al. Physical growth: National Center for Health Statistics percentiles. Am J Clin Nutr 1979; 32: 607-29. 